\title{
A UTILIZAÇÃO DE FERRAMENTAS DA QUALIDADE COMO ESTRATÉGIA DE MELHORIA ORGANIZACIONAL: ESTUDO DE CASO NA CERÂMICA ALFA
}

\author{
Paulo Fernando Vieira (FACULDADE CESUC) paulo_fatality@ hotmail.com \\ Mara Rúbia da Silva Miranda (UFMS) mara_miranda@ufms.br
}

\begin{abstract}
Resumo
O objetivo único de apenas lucrar das organizações que buscam ser competitivas, tornou-se um paradigma ultrapassado. As empresas atualmente estão buscando lucrar e, ao mesmo tempo satisfazer os seus clientes com produtos e/ou serviços de qualidade. O fato é que qualidade não significa apenas satisfazer os clientes, mas também padronizar os processos organizacionais visando um melhor controle do sistema. Desta forma, várias organizações têm buscado ferramentas básicas e até mesmo complexas para a conquista da qualidade total. Tendo em vista esta constante busca por qualidade e melhorias no processo no contexto atual, este trabalho tem como objetivo mostrar aplicar ferramentas da qualidade como foco de melhoria organizacional numa empresa de Cerâmica. A metodologia para a realização do trabalho foi o estudo de caso na empresa mencionada neste trabalho como Cerâmica Alfa, onde foram feitas diversas observações in loco objetivando diagnosticar os problemas levantados, bem como entrevistas com os colaboradores. A conclusão obtida com a implementação das ferramentas foi que a organização consegue diminuir os seus custos da não qualidade, consequentemente aumentar a sua lucratividade ao alavancar suas vendas pelo fato de ter uma maior satisfação do seus clientes.
\end{abstract}

Palavras-chaves: Ferramentas; Qualidade; Estratégia; Competitividade.

\section{Introdução}

Com a constante mudança de mercado e o crescimento de organizações concorrentes, é essencial a utilização de um gerenciamento de qualidade que vise a satisfação em um determinado seguimento de mercado. A qualidade é uma abordagem essencial que vem sendo desenvolvida no mundo inteiro a milhares de ano, passando por diversas eras e, assim sendo, cada vez mais estruturada em sua história evolutiva em diversos países como Japão e como ela se desenvolveu no Brasil.

A busca pela qualidade tem sido sem dúvidas uma das grandes prioridades para as organizações se manterem competitivas. O fato é que muitas têm enfrentado dificuldades para aplicar uma adequada gestão da qualidade, pois não têm um modelo de conscientização até mesmo no nível estratégico. Ou seja, alegam que não vale apena ter custo com a qualidade, pois não há um custo-benefício tão significante para que haja toda uma reestruturação nos processos.

Este trabalho visa mostrar a importância de se aplicar melhorias na qualidade de seus produtos, uma vez que a qualidade é um dos quesitos fundamentais para satisfação dos clientes. Além disso, verificar a aplicação das ferramentas para a melhoria como um todo no processo produtivo de uma empresa e sua implicação nos custos operacionais. Vai ser abordado também como é a melhoria contínua em uma organização, seus benefícios e seus resultados obtidos em um ciclo produtivo de uma empresa de cerâmica.

A empresa estudada é uma Cerâmica a que denominamos aqui de Alfa. A justificativa para se realizar o estudo nesta empresa é pela reclamação dos próprios funcionários acerca da falta de padronização dos processos que 
acabava gerando um produto de baixa qualidade. Em um momento em que o Brasil vive de crise econômica, as empresas necessitam de alguma forma buscar a redução dos seus custos para conseguir sobreviver no mercado. Muitas das vezes este custo não é diagnosticado corretamente e, além disso a empresa perde vendas, abrindo caminho para o concorrente. Assim, se torna importante aplicar ferramentas de qualidade para auxiliar na melhoria organizacional, contribuindo como estratégia para uma maior competitividade.

\section{Fundamentação e conceitos}

\subsection{Qualidade}

Juran (1992) define a qualidade como sendo uma adequação ao uso por meio da percepção das necessidades dos clientes e aperfeiçoamentos introduzidos a partir de patamares já alcançados. O seu foco de atenção era no planejamento, controle e melhoria e as ferramentas eram metodologias para a solução dos problemas.

Já para Crosby (1979) apud Contador (2010) a visão da qualidade estava relacionada ao cumprimento das especificações estabelecidas para alcançar a satisfação dos clientes.

Segundo Contador (2010) o termo qualidade, numa visão moderna, abriga simultaneamente a perspectiva do mercado e da empresa. Para o autor, qualidade é um fator estratégico e satisfação do cliente com a menor utilização de recursos é necessário para a competitividade. Desta forma, a qualidade se torna primordial na organização, pois por meio dela é possível sustentar a competição.

Foram vários os pioneiros da qualidade, como por exemplo, Deming, Ishikawa, Juan, Crosby, entre outros. De modo geral tinham o conceito de qualidade em diferentes aspectos como, por exemplo, adequação ao padrão, adequação ao uso, adequação às necessidades dos clientes etc. No passar do tempo todos estes conceitos foram se adaptando ao contexto atual e, hoje todas as empresas têm uma concepção da qualidade, mas todas elas visam o aumento da competitividade e se manter no mercado.

Desta forma, a importância da qualidade está na busca do aumento das vendas e produção, com a finalidade de continuamente aumentar o valor agregado e a sobrevivência frente a um mercado altamente competitivo.

\subsection{Ferramentas da Qualidade}

Para Campos (1999), "a Garantia da qualidade é uma função da empresa que tem como finalidade confirmar que todas as atividades da qualidade estão sendo conduzidas da forma requerida."

A gestão da qualidade em produtos e serviços é questão de sobrevivência para as empresas na atualiade (JURAN, 1992).

Para Ballestero-Alvarez (2012) as organizaões não devem se esquecer de contemplar a própria filosofia de qualidade. Ou seja, ter uma gestão da qualidade orientada para o cliente, visão do lucro, centrar o funcionário no desempenho de suas atividades, ter consciência social e ambiental etc.

Garantia da qualidade é o selo que qualquer fornecedor deseja ter na parede de sua empresa, demonstrando que tem de seus clientes a credibilidade esperada. Para isso, se faz necessário o uso de Ferramentas da qualidade.

(SOCO e GOMES, 2011). 
Existem inúmeras ferramentas de qualidade e atualmente as empresas criam suas próprias ferramentas ou aprimoram as existentes de modo a atender as necessidades de seus processos internos. Abaixo são listadas algumas segundo Balletero Alvarez (2012):

a) Brainstorming: significa "tempestade de ideias", onde todos os envolvidos com o processo podem participar da geração de ideias. Sua principal vantagem é que aqueles que estão diretamente ligados ao processo e que conhecem na prática o problema em questão participam expondo suas ideias. Ao final, é feito um levantamento e reflexão de todas as ideias ouvidas para um consenso decisivo.

b) Diagrama de Causa e Efeito (Espinha de Peixe): conhecido também como diagrama de Ishikawa. É uma ferramenta gráfica usada para mostrar a relação entre causas e efeitos ou alguma características de qualidade e os fatores envolvidos. Ele permite estruturar hierarquicamente as causas, oportunidades de melhoria e os efeitos sobre a qualidade dos produtos;

c) Fluxograma: é usado para diagramar sequencialmente as etapas de um processo qualquer. Constitui importante auxiliar, pois concede a visão global do fluxo, de suas falhas e de seus gargalos;

d) Diagrama de Pareto: também chamado de diagrama ABC, 80-20, 70-30, é um gráfico de barras que ordena as frequências das ocorrências, da maior para a menor, permitindo a priorização dos problemas. Seu objetivo principal é detectar quais problemas sao fundamentais e separá-los dos mais comuns. Exemplificando: $80 \%$ das causas provocam $20 \%$ dos problemas e seu inverso também é verdadeiro;

e) Folha de verificação ou folha de coleta de dados: o objetivo desta folha é gerar uma massa clara de dados, qua facilite a análise e o tratamento posterior. Esta folha deve conter no seu formulário todas as informações necessárias, como por exemplo, o responsável pelas medições, datas, metodologia de coleta de dados entre outros assuntos que a empresa julgar necessário;

f) PDCA: conhecido também como ciclo de Deming, sua premissa está em desenvolver os processos repetitivos por meio de sua aplicação para obter o controle de todo o processo produtivo.

O conceito PDCA é atualmente trabalhado na melhoria contínua em muitas empresas de processos de gestão. O PDCA é um ciclo que envolve 4 etapas que são: Plan, Do, Check e Act.

Segundo Campos (2004), o ciclo PDCA tem 8 passos que são os seguintes:

1. Identificação do problema.

2. Análise do Fenômeno (problema);

3. Análise do Processo;

4. Elaborar os planos de ação para atingir as metas;

5. Executar os planos de ação;

6. Controlar a eficiência dos planos de ação Realizada x Planejado;

7. Agir corretivamente, se necessário;

8. Estabelecer os padrões caso o resultado seja alcançado. 
Figura 1 - Ciclo PDCA

(Ciclo para Atingir Metas)

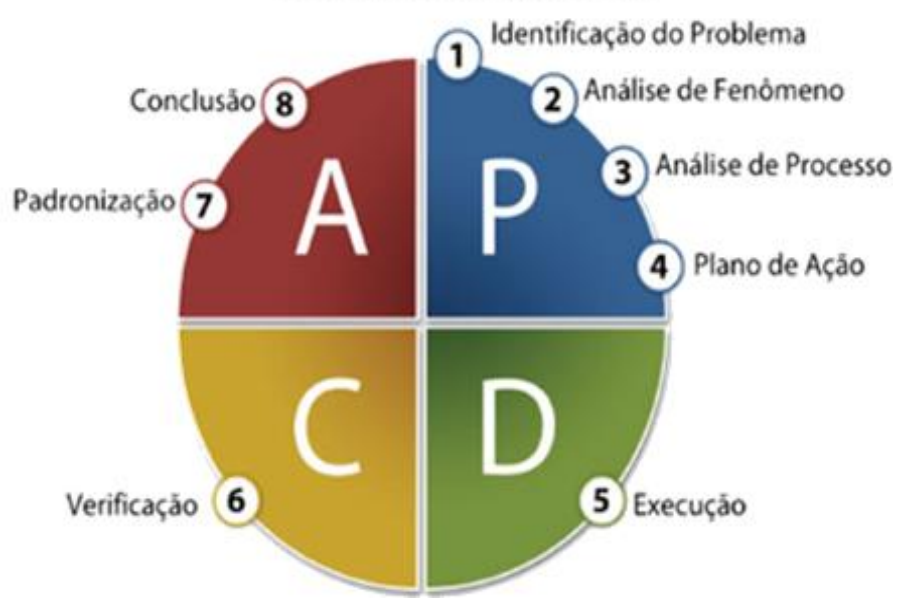

Fonte: Peters (1998)

\subsection{Custos da qualidade}

Segundo Carpinetti (2010), a gestão da qualidade no nível de operações de produção visa a melhoria do desempenho no atendimento dos requisitos dos clientes e ao mesmo tempo a redução dos custos da não qualidade. Como a gestão da qualidade implica em investimentos, a análise de custo versus benefícios de um investimento também deve ser um fator a ser ponderado nas decisões relacionadas à melhoria de resultados $\mathrm{e}$ redução dos custos da não qualidade. De um modo geral, os custos da qualidade englobam os custos decorrentes da falta de qualidade, assim como os custos para se obter qualidade.

Segundo Oliveira et al (2003), o custo da qualidade é classificado como um custo de prevenção, o qual ocorre quando se busca prevenir problemas. Incluem o que se gasta durante a observação e indentificação de problemas antes da execução ou produção de determinado bem ou serviço. Deve-se lembrar, aindam que a necessidade de capacitação do pessoal envolvido diretamente no processo de produção não pode ser colocado em segundo plano, pois a execução de um processo produtivo por agentes não qualificados também pode incorrer em grades prejuízos, levando, inclusive, ao desperdício dos fatores de produção utilizados.

\subsection{Custos da não-qualidade}

Para Oliveira et al (2003), os custos de falhas, tanto as internas como as externas, poderão ser definidos como custos da má-qualidade assim como os custos de avaliação, que derivam da necessidade de separar o ruim do bom. Ainda que tenham sido gerados pelas atividades da função qualidade, esses custos só passaram a existir em consequiência de falhas terem acontecido.

A partir destas categorias, sabe-se que as falhas são um fenômeno aleatório. Ninguém decide quando uma falha vai acontecer em uma empresa. Se um determinado conjunto de causas se acumula por vários motivos, uma falha simplesmente acontece e determina suas conseqüências. 
a) Custos da avaliação: São especificamente voltados para o controle de qualidade. Ocorrem quando os agentes envolvidos diretamente no processo de produção checam a possibilidade de existência de problemas e erros que podem acontecer durante o processo de fabricação ou execução do produto e serviço. Podem ser utilizados muitos métodos como Controle Estatístico de Processo mediante a adoção de planos de amostragem e analises matemático - estatística, e também os instrumento de auditoria da qualidade e pesquisas de satisfação dos consumidores;

b) Custos de falhas internas: Ocorrem na medida em que são detectados erros na operação interna, como problemas com peças materiais refugados ou retrabalhos. Incluem também a perda de tempo durante o processo de produção, bem como a falta de concentração dos agentes envolvidos na solução dos erros ocorridos. Por isso e necessário identificar erros internos apartir de um controle rígido dos fatores de produção utilizados no processo, bem como controlar o tempo de desempenho das funções exercidas pelos agentes produtivos. Nesse sentido, a especialização e a qualificação dos agentes envolvidos tornam-se importantes, na medida em que o controle a envolver-se também com a qualificação da mão de obra;

c) Custo de falhas externas: Esse erro ocorre quando o produto ou serviço defeituoso chega as mãos dos consumidores após a sua entrega do mercado. Os consumidores são afetados em relação a confiança que tem no produto ou serviço e, consequentemente, na empresa.

\section{Análise dos resultados}

\subsection{A empresa Cerâmica Alfa}

A Cerâmica Alfa é uma empresa industrial de produtos de construção e, atualmente é líder de vendas na cidade, onde há mais de oito anos leva a qualidade e requinte em seus produtos. Entre seus produtos se destacam os tijolos 09x14×24 e 09x14x29, lajotas, além de tijolos a vista e refratários.

A empresa conta, na planta em questão, com aproximadamente 43 funcionários, ou seja, uma empresa de pequeno porte e que possui uma capacidade produtiva em torno de 46000 tijolos por dia que podem variar conforme o produto.

Os processos produtivos da empresa são em linhas gerais:

a) Processamento da argila em maquinas;

b) Secagem do produto em estufas;

c) Queima do material em fornos.

Na Figura 2 é possível analisar todo o processo produtivo através da ferramenta - fluxograma.

Os dados foram coletados através de arquivos da empresa, reuniões semanais e pesquisa com clientes e fornecedores. 
Figura 2 - Fluxograma do processo produtivo da empresa

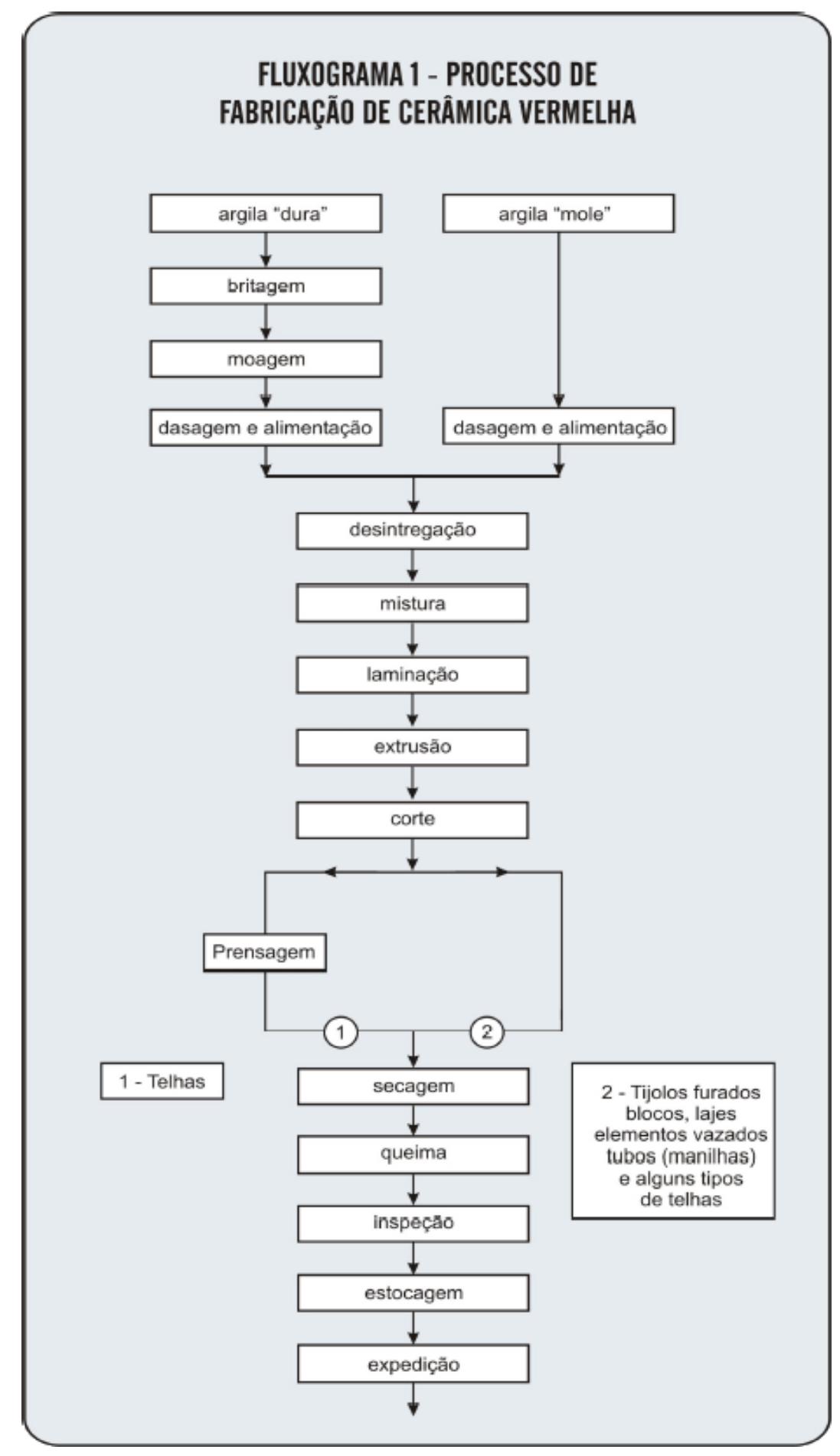

Fonte: Cerâmica Alfa

A meta da equipe era aumentar o índice de satisfação do cliente e, ao mesmo tempo recuperar o seu espaço no mercado que estava sendo conquistado pela concorrência que aproveitou a falta de qualidade dos produtos da empresa. Ou seja, a equipe deveria reduzir o índice de material retrabalhado na produção e ao mesmo tempo aumentar a qualidade de seu material além de quantificar os gastos com a qualidade e o retorno obtido. 
Os possíveis defeitos internos e seus respectivos códigos são:

a) Pouca resistência a umidade, I-01;

b) Material com rachaduras laterais, I-02;

c) Material com pouca firmeza ou sem resistência, I-03;

d) Material com canto quebrado, I-04;

e) Material com variação de medida tanto vertical como horizontal, I-05.

Esses defeitos geram custos não só de material devolvido retrabalho na produção, grande custo de mão de obra, material sucateado.

Para que possa entender melhor os defeitos foram separados por local de possível origem. I-01, I-03 (Queima do material em fornos); I-02, I-05 (Processamento da argila em máquinas) ;I-04 (Secagem do Material em estufas). Com referência para coleta de dados no início dos trabalhos da equipe, foi considerada a média que o processo vinha apresentando antes de implementar as ações de melhorias, conforme irão mostrar nos próximos tópicos.

\subsection{Aplicação das ferramentas}

Uma das ferramentas utilizadas pela equipe para aumentar a produtividade na empresa foi a ferramenta de Brainstorming. A equipe buscou valorizar todos os colaboradores da empresa através da exposição de suas ideias e, após a "tempestade de ideias" foi possível selecionar os dados necessários para a análise do problema. O que toda a equipe fez foi elaborar uma folha de verificação para coletar dados qualitativos e quantitativos para que fosse possível construir determinados gráficos de índices de retrabalho e quantidade de vendas. Na Figura 3 é possível analisar o gráfico de vendas nos últimos 8 meses antes de implementar as ferramentas de qualidade. Neste gráfico verifica-se que o mês 1 a empresa teve mais vendas e depois as unidades vendidas tiveram uma queda. Diagnosticar esta perda de venda estava sendo o foco da equipe, já que a empresa estava perdendo fatia no mercado e não sabia os motivos.

Figura 3 - Gráfico de vendas em milhares de unidades vendidas (antes da melhoria)

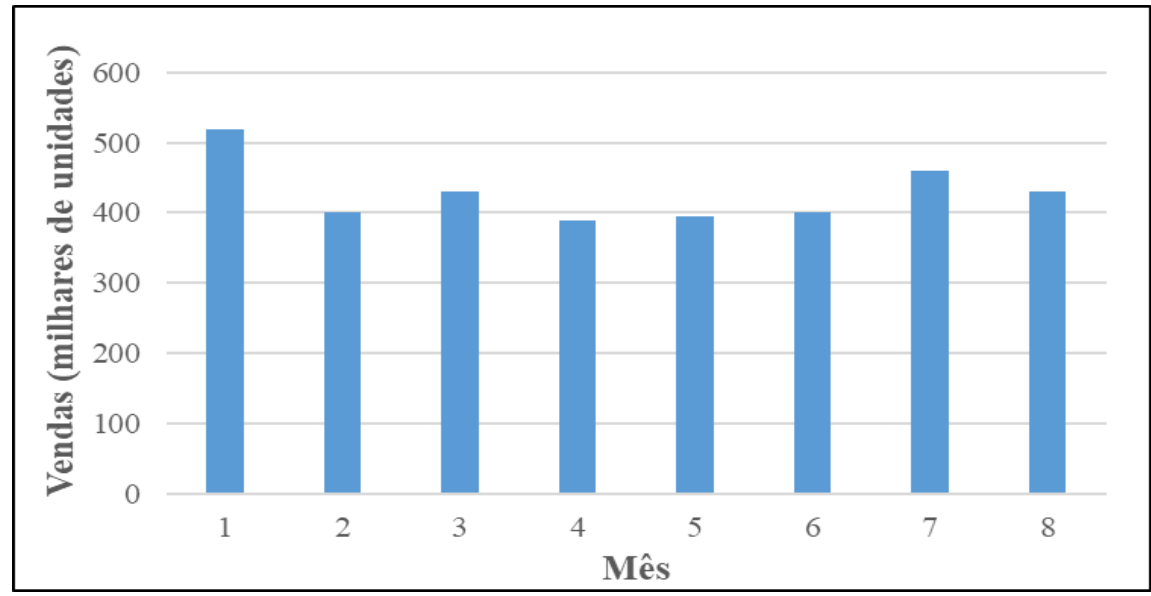

Fonte: dados da empresa (elaborado pelo autor) 
Já na Figura 4 é possível observar que todo mês no mínimo $8 \%$ da produção são provenientes de materiais retrabalhados. Ou seja, materiais estes que passaram pelo processo de queima, mas não estão com qualidade para serem comercializados para o consumidor final e, pelo fato de ainda não terem endurecedido podem ser retrabalhados para melhorar a qualidade e acabamento.

Figura 4 - Gráfico da porcentagem de material retrabalhado (antes da melhoria)

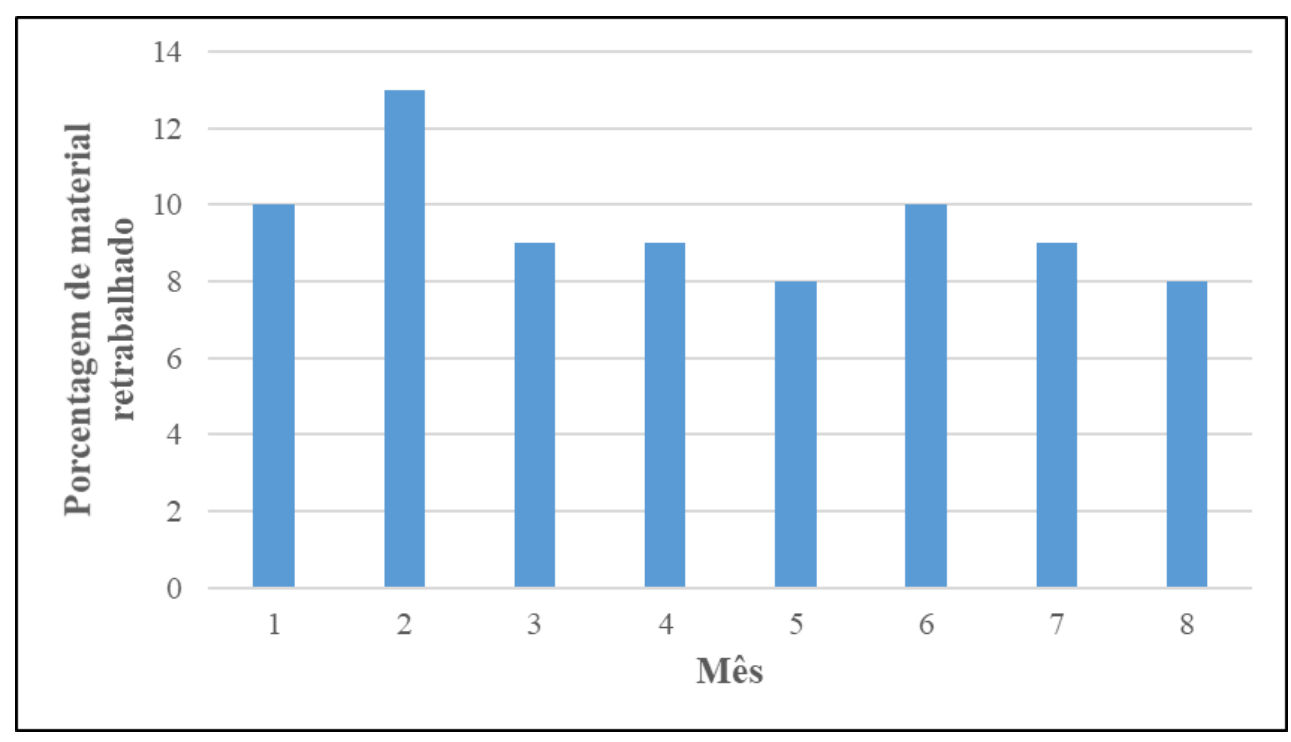

Fonte: dados da empresa (elaborado pelo autor)

É importante ressaltar nesta fase do processo de material retrabalhado que há um custo da não-qualidade. A organização perde tempo neste reprocessamento para melhorar a qualidade, além de utilizar vários outros recursos que poderiam estar sendo usados para outros fins.

O Quadro 1 mostra a programação da produção dos produtos da empresa.

Quadro 1 - Quantidade produzida dos produtos da empresa

\begin{tabular}{|c|c|c|}
\hline DIA & DESCRIÇÃO DO PRODUTO & QUANTIDADE \\
\hline 1 & Tijolo Furado 09x14×29 & 42000 \\
\hline 2 & Tijolo Furado 09x14x29 & 35000 \\
\hline 3 & Tijolo Furado 09x14×24 & 46000 \\
\hline 4 & Lajota $09 \times 20 \times 30$ & 34000 \\
\hline 5 & Tijolo Furado 09x14x29 & 40000 \\
\hline 6 & Tijolo Furado 09x14x24 & 22000 \\
\hline 7 & DOMINGO & - \\
\hline 8 & Tijolo Refratário 05x09x19 & 55000 \\
\hline 9 & Tijolo Furado 09x14x29 & 39000 \\
\hline 10 & Tijolo Furado 09x14x24 & 42000 \\
\hline
\end{tabular}

Fonte: dados da empresa (elaborado pelo autor)

É possível observar neste quadro que o produto Tijolo Furado 09x14x29 é o produto com maior demanda e por isso sua produção é maior. Esta é um tipo de empresa que necessita de uma programação bastante precisa, já que possui uma única linha para diversos tipos de produtos. E isto mostra outra justificativa para padronizar os processos e buscar a melhoria contínua através da qualidade. 
A Figura 5 mostra o gráfico de causa e efeito, também chamado de gráfico de espinha-de-peixe. Dentro dos 6M’s (Material, Máquina, Mão de Obra, Método, Meio Ambiente e Medida) é possível identificar quais são as causas que interferm prioritamente no efeito qualidade. Este levantamento foi possível com o brainstorming e método de observação in loco. Ou seja, foram observados todos os processos dentro da organização, objetivando diagnosticar as principais causas da perda da qualidade do produto.

Figura 5 - Gráfico Espinha-de-Peixe

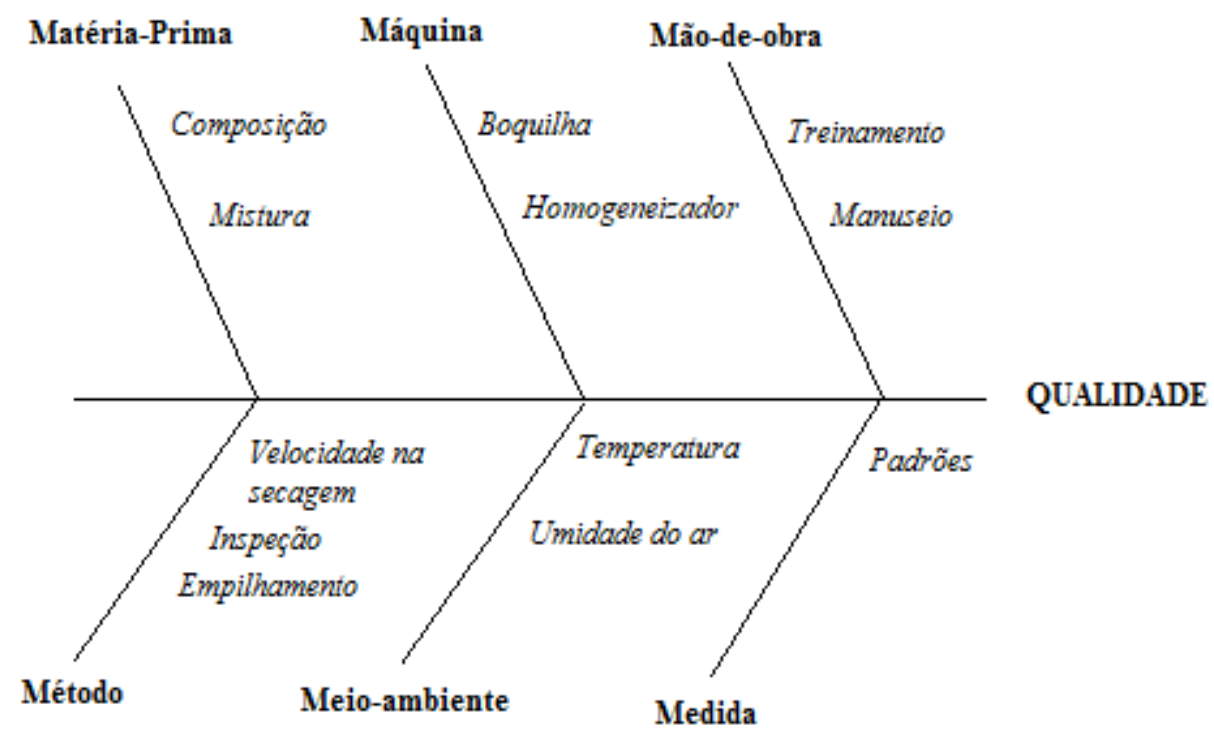

Fonte: dados da empresa (elaborado pelo autor)

Com esta figura de causa de efeito, os colaboradores foram incentivados a monitorarem estas causas a fim de dignosticarem as que estavam afetando na qualidade dos produtos da empresa. No período de 30 dias, foram observados algumas discrepâncias no fator Mão de Obra, já que alguns colcaboradores não estavam executando as atividades e manuseando os equipamentos de forma adequada que acabava interferindo fator Máquina e Medida. Não havia uma norma ou padrão a ser adotado e por isso a forma de adotar o Método também estava comprometendo a qualidade final do produto. Sabendo que a padronização através de manuais poderia então levar mais tempo, a gestão decidiu implementar algumas ações rápidas para aumentar a qualidade do produto mediante os resultados percebidos das causas levantadas. Foram mais 15 dias de observação e treinamento em cima das causas. Foi feito um trabalho de conscientização e mostrado aos colaboradores os resultados antes da melhoria e os após a melhoria.

A Figura 6 mostra o gráfico das vendas após a implementação das melhorias na qualidade. Na Figura 7 é possível verificar a melhoria obtida no processo da empresa através da redução da porcentagem retrabalhada. 
Figura 6 - Gráfico de vendas em milhares de unidades vendidas (após a melhoria)

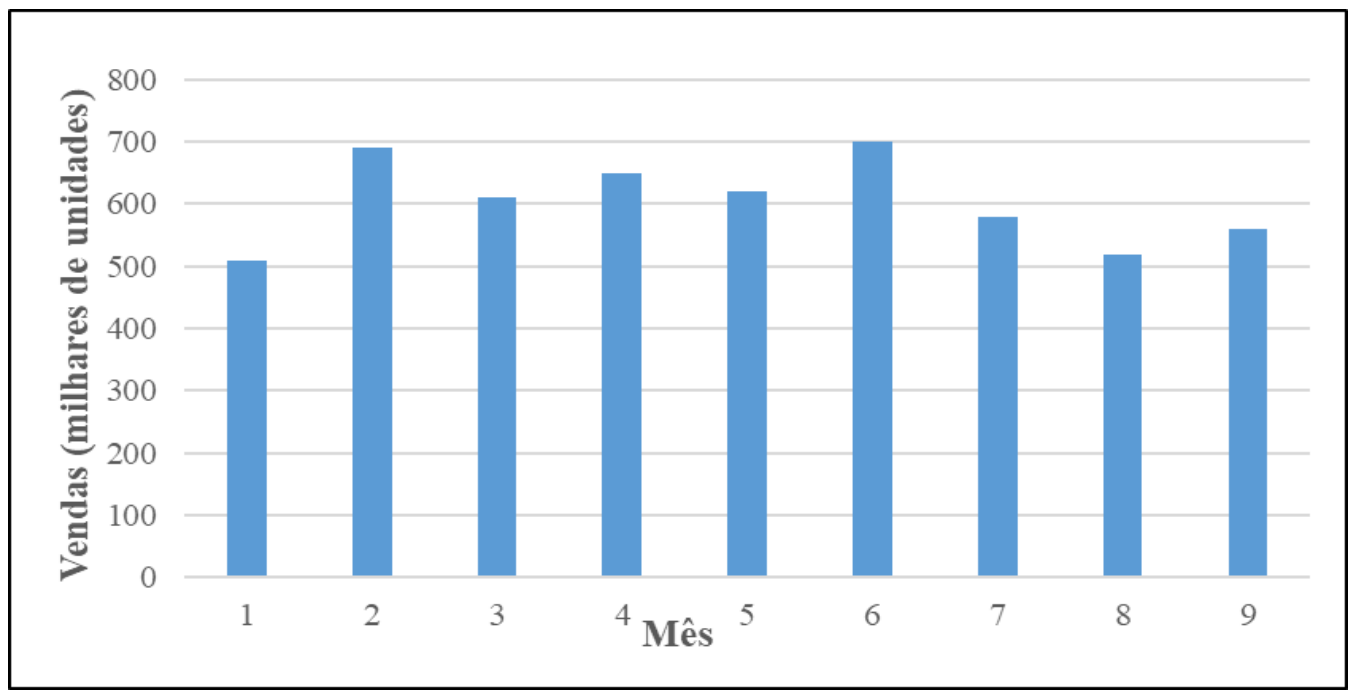

Fonte: dados da empresa (elaborado pelo autor)

Figura 7 - Gráfico da porcentagem de material retrabalhado (após a melhoria)

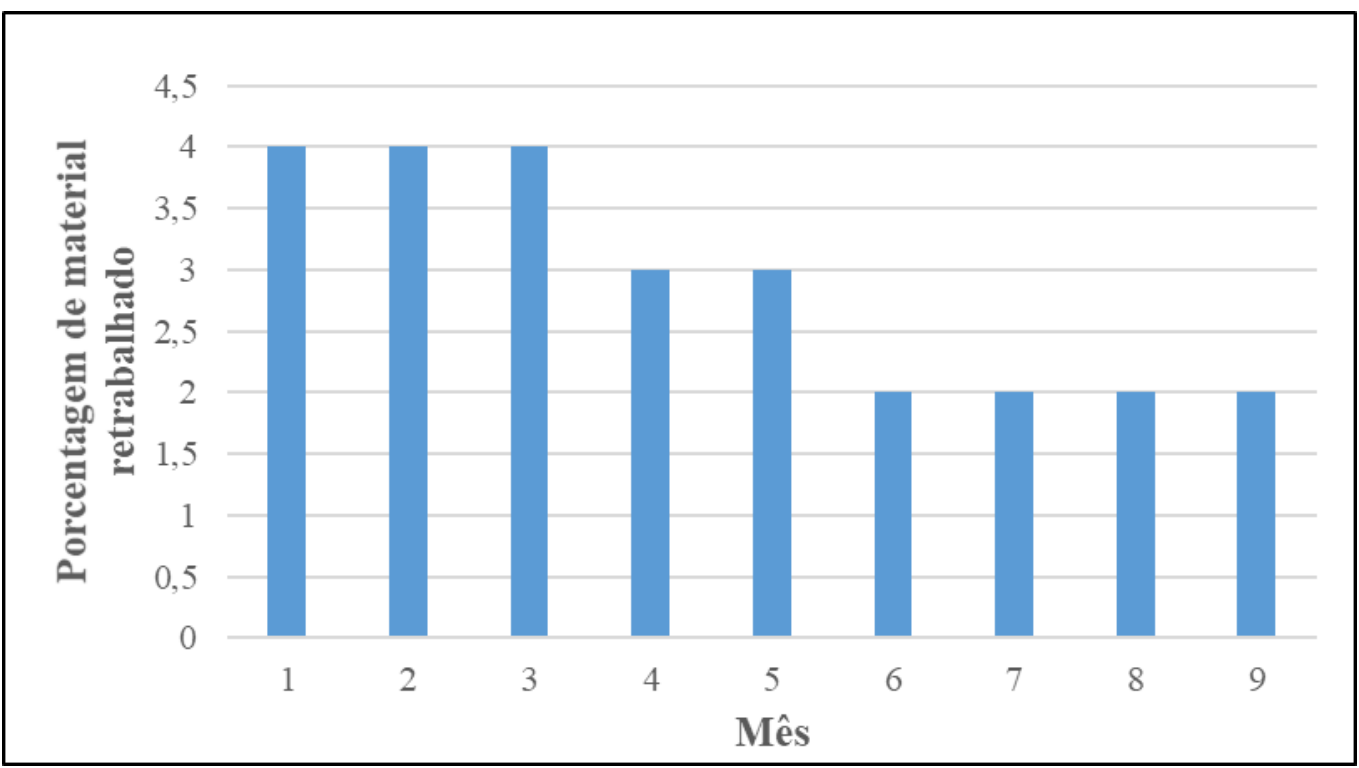

Fonte: dados da empresa (elaborado pelo autor)

Pode-se observar que a empresa teve um aumento em suas vendas de no mínimo 100 mil peças por mês ao adotar a melhoria.

O material retrabalhado que antes era de 8 a $13 \%$, passou para 2 a $4 \%$. Nos últimos meses a empresa vem conseguindo manter a $2 \%$ a porcentagem de materiais retrabalhados. Isto foi um grande ganho no que se refere a qualidade e principalmente na redução do custo da não qualidade. 


\section{Considerações finais}

Os resultados apresentados pela equipe mostrou o comprometimento e a busca constante pela qualidade. Como foram verificados nos gráficos, os índices de material retrabalhado diminuiram de $13 \%$ para $2 \%$. Em números isso significa um ganho na eficiência, pois ao considerar a produção de 560 mil unidades vendidas no mês de março de 2013, isso significa que 72.800 unidades foram retrabalhadas quando se trata de $13 \%$. Considerando a porcentagem de $2 \%$, isso representa somente 11.200 unidades de material retrabalhado. Ainda representa um alto índice, mas a empresa está estudando outras estratégias para serem implementadas visando esta redução e aperfeiçoamentos nos processos como um todo.

Outro fator importante a ser destacado é a presença do ciclo PDCA no processo de melhoria da qualidade. Foi possível verificar que houve uma identificação do problema, uma execução dos planos de ação que neste caso, seria a aplicação das ferramentas, uma verificação que corresponde ao controle das ações implementadas e por fim, uma padronização da qualidade.

Além disso, por se tratar de uma empresa de pequeno porte, a organização juntamente com os funcionários não utilizaram totalmente as ferramentas básicas da qualidade. O treinamento e conscientização em empresas de pequeno porte é um fator de extrema importância para que todos trabalhem por um único objetivo. De qualquer forma, a ferramenta brainstorming foi a ferramenta que mais foi utilizada, pois além de ser muito simples, os funcionários se sentem motivados, pois estão fornecendo idéias acerca dos problemas gerais da empresa.

Contudo, conclui-se que a aplicação de ferramentas básicas contribui para o aumento de competitividade da organização, pois intefere positivamente nos principais indicadores e metas da empresa.

Como propostas para trabalhos futuros dentro da organização, propõe-se dar continuidade na implementação das ferramentas de qualidade, aplicando desta vez num período maior para diagnóstico ferramentas mais complexas, além de dados quantitativos como os custos da não qualidade para que os gestores apoiem o desenvolvimento de ações de melhorias contínuas dentro da organização.

\section{Referências}

BALLESTERO-ALVAREZ, M.E. Gestão da qualidade, produção e operações. 2ed. Editora Atlas, 2012.

CAMPOS, V.F. TQC Controle da qualidade total (no estilo Japonês). Editora de Desenvolvimento Gerencial. Belo Horizonte, 1999.

CAMPOS, V. F. Gerenciamento da rotina do trabalho do dia-a-dia. 8. ed. Belo Horizonte: Editora de Desenvolvimento Gerencial, 2004.

CARPINETTI, L.C.R. Gestão da Qualidade : 1 $^{a}$ edição, São Paulo: Editora Atlas, 2010

CONTADOR, J.C. Gestão de Operações. A Engenharia de Produção a serviço da modernização da empresa. 3ed. Editora Blucher, 2010.

CROSBY, P.B. Quality is free. New York New American Library, 1979.

JURAN, J.M.; GRYNA, F.M. Controle da qualidade. Revisão Técnica Gregório Bouer e José J.A. Ferreira. São Paulo: Makron Books, 1992, 9v. 
OLIVEIRA, O.J.et al. Gestão da Qualidade. Tópicos Avançados. Editora Cengage Learning, 2003.

PETERS, T. O círculo da inovação. São Paulo: Harbra, 1998.

SOCCO, A.P.; GOMES, T.S. O custo da não-qualidade: um estudo de caso em uma empresa do ramo automobilístico. Revista CEPPG - CESUC - Centro de Ensino Superior de Catalão, Ano XIV, No 25 - $2^{\circ}$ Semestre/2011. 